УДК $541.8+669.295$

DOI 10.26732/2618-7957-2018-3-157-164

\title{
CВ-СИНТЕЗ $\mathrm{TiB}_{2}-\mathrm{MgAl}_{2} \mathrm{O}_{4}$ КОМПОЗИТОВ ДЛЯ ЖАРОСТОЙКИХ ПОКРЫТИЙ
}

\author{
Н. И. Афанасьев, Н. И. Радишевская, О. К. Лепакова, \\ А. Ю. Назарова, В. Д. Китлер \\ Томский научный ичентр СО РАН, \\ 2. Томск, Российская Федераџия
}

\begin{abstract}
Бориды металлов широко используются в качестве теплоизоляционных материалов, но в условиях высокотемпературных окислительных сред эффективность их применения значительно снижается. Для повышения термостойкости конструкционных материалов на основе диборида титана и предотвращения роста кристаллов ТіВ няли добавки химически стойкой алюмомагнезиальной шпинели, обладающей огнеупорными свойствами. Целью данной работы являлось исследование структуры композита $\mathrm{TiB}_{2}-\mathrm{MgAl}_{2} \mathrm{O}_{4}$, полученного методом самораспространяющегося высокотемпературного синтеза двумя способами. Первый - $C B$-синтез диборида титана из его элементов с добавкой алюмомагнезиальной шпинели. Другим способом решения получения термостойкого композиционного материала является $C B$-синтез алюмомагнезиальной шпинели с добавлением готового диборида титана. Наилучшие результаты получены первым способом. Структура с равномерным распределением мелких зерен ТіВ ${ }_{2}$ синтезирована с добавкой $25 \%$ масс. $\mathrm{MgAl}_{2} \mathrm{O}_{4}$. Составы исследовали рентгенофазовым анализом (ДРОН-зМ, фильтрованное Сu- $k_{\alpha}$-излучение), ИК-спектроскопией (Nicolet 57Oо) $u$ сканирующей электронной микроскопией (Philips SEM 515). Полученный материал представляет собой композит, в котором частицы ТіВ $B_{2}$, имеющие размер, не превышающий 5 мкм, равномерно распределены в матрице алюмомагнезиальной шпинели.
\end{abstract}

Ключевые слова: диборид титана, алюмомагнезиальная шпинель, самораспространяющийся высокотемпературный синтез, композиты.

\section{Введение}

Карбиды и бориды металлов широко используются в качестве теплоизоляционных материалов, однако область их применения ограничена в результате окисления в агрессивных средах при высоких температурах. Для повышения их огнеупорности дополнительно вводится алюмомагнезиальная шпинель $\left(\mathrm{MgAl}_{2} \mathrm{O}_{4}\right)$, имеющая температуру плавления $2135^{\circ} \mathrm{C}$, что соответствует высшей категории огнеупорности [1]. Для синтеза таких керамических материалов применяют магний- и алюмотермические процессы синтеза. Так, с помощью металлотермического восстановления в системе $\mathrm{TiO}_{2}-\mathrm{MgO}-\mathrm{Al}_{2} \mathrm{O}_{3}-\mathrm{Al}$ получены огнеупорные материалы на основе $\mathrm{MgAl}_{2} \mathrm{O}_{4}$ и карбонитридов титана [2]. Высокопрочный пористый керамический материал, в состав которо-

(C) Афанасьев Н. И., Радишевская Н. И., Лепакова О. К., Назарова А. Ю., Китлер В. Д., 2018 го входят $\mathrm{MgAl}_{2} \mathrm{O}_{4}, \mathrm{TiB}_{2}, \mathrm{TiO}_{2}, \mathrm{Al}_{4} \mathrm{~B}_{2} \mathrm{O}_{6}, \mathrm{Mg}_{2} \mathrm{~B}_{2} \mathrm{O}_{5}$, синтезирован в системе $\mathrm{TiO}_{2}-\mathrm{B}_{2} \mathrm{O}_{3}$ - $\mathrm{Al}$ с добавками $\mathrm{MgO}$. Его можно использовать в качестве катализаторов при температурах $600-700{ }^{\circ} \mathrm{C}$ в открытой атмосфере [3;4].

При получении тугоплавких неметаллических композиционных соединений с заданными свойствами широко используется метод самораспространяющегося высокотемпературного синтеза (CBC). С применением этого метода в данной работе получен композиционный материал на основе диборида титана и химически стойкой и огнеупорной алюмомагнезиальной шпинели, которая экранировала частицы $\mathrm{TiB}_{2}$ и затормаживала протекание высокотемпературных твёрдофазных окислительных реакций в процессе эксплуатации материала.

Получали такой материал двумя способами. Первый - синтез диборида титана из его элементов с добавкой алюмомагнезиальной шпинели. Другим способом решения получения термостойкого композиционного материала является 
синтез алюмомагнезиальной шпинели методом СВС с добавлением готового диборида титана.

Целью данной работы является получение методом СВС термостойкого композиционного материала на основе $\mathrm{TiB}_{2}$ и $\mathrm{MgAl}_{2} \mathrm{O}_{4}$ двумя вышеперечисленными способами и исследование фазового состава и микроструктуры полученных материалов.

\section{Материалы и методы исследования}

Для приготовления реакционных смесей для синтеза композиционного материала первым способом использовали просушенные в вакууме при температуре $200{ }^{\circ} \mathrm{C}$ в течение 2 часов порошки титана марки ТПП-8 (содержание титана $\sim 96 \%$, размер частиц < 160 мкм, ОАО «Ависма»), алюмомагнезиальной шпинели (ТУ 6-09-01-136) и бора аморфного (Б-99А-ТУ-6-02-585-75). Было приготовлено 4 смеси различного состава: $90 \%$ $(\mathrm{Ti}+2 \mathrm{~B})+10 \% \mathrm{MgAl}_{2} \mathrm{O}_{4} ; 75 \%(\mathrm{Ti}+2 \mathrm{~B})+25 \%$ $\mathrm{MgAl}_{2} \mathrm{O}_{4} ; 60 \%(\mathrm{Ti}+2 \mathrm{~B})+40 \% \mathrm{MgAl}_{2} \mathrm{O}_{4} ; 55 \%$ $(\mathrm{Ti}+2 \mathrm{~B})+45 \% \mathrm{MgAl}_{2} \mathrm{O}_{4}$. Порошки тщательно перемешивали до получения однородной шихты, из которой на гидравлическом прессе формовали пористые (40-45 \%) цилиндрические образцы диаметром 20 и длиной 30-32 мм. Синтез проводили в установке постоянного давления в атмосфере аргона при давлении 6 атм. Воспламенение образцов осуществляли с помощью вольфрамовой спирали.

В качестве исходных реагентов для второго способа использовали смеси порошков оксидов магния $\mathrm{MgO}$ и алюминия $\mathrm{Al}_{2} \mathrm{O}_{3}$ квалификации «ч», порошок алюминия марки АСД-4 дисперсностью менее 30 мкм с добавкой аморфного бора (Б-99А-ТУ-6-02-585-75) в количестве 4 \% масс. с размером частиц 1-5 мкм и нитрат магния $\mathrm{Mg}\left(\mathrm{NO}_{3}\right)_{2} \cdot 6 \mathrm{H}_{2} \mathrm{O}$ «хч». В смесь добавляли поро- шок $\mathrm{TiB}_{2}$ (10\% масс. и $20 \%$ масс.), полученный СВС методом. Синтез композита осуществляли в стаканчиках из металлической сетки на воздухе при атмосферном давлении, которые помещались в градиентную печь сопротивления. Для синтеза использовали образцы насыпной плотности, воспламенение которых осуществляли в верхней части образца, где температура печи была максимальной.

Температуры горения определяли вольфрам-рениевой термопарой ВР5-BР20 диаметром 100 мкм, регистрацию данных осуществляли с помощью аналого-цифрового преобразователя ЛА-20USB, соединённого с персональным компьютером. Составы полученных материалов подтверждены рентгенофазовым анализом (Дрон-3М, фильтрованное Со k $\alpha$-излучение), ИК-спектроскопией (ИК-Фурье спектрометр Nicolet-5700). Для изучения микроструктуры использовали оптический микроскоп (Axiovert $200 \mathrm{M})$ и растровый электронный микроскоп SEM-515 (Philips). Испытания на микротвердость проводили на микротвердомере ПМТ-3 при нагрузке на пирамидку Виккерса 100 г в соответствии с требованиями ГОСТа 9450-60.

\section{Результаты и обсужАение}

Для смеси порошков с соотношением компонентов Ті:B = 1:2 адиабатическая температура горения составляет $\mathrm{T}_{\text {ад }}=3190 \mathrm{~K}$ [5]. Высокая температура синтеза диборида титана способствуют расплавлению алюмомагнезиальной шпинели, которая, растекаясь по поверхности его зёрен, формирует матрицу, обеспечивающую защиту поверхности $\mathrm{TiB}_{2}$ шпинелью. В данном случае алюмомагнезиальная шпинель $\mathrm{MgAl}_{2} \mathrm{O}_{4}$ по отношению к смеси $(\mathrm{Ti}+\mathrm{B})$ является инертом. В табл. 1 приведены физико-химические свойства шпинели и диборида титана [6;7].

Физико-химические свойства соединений

Таблица 1

\begin{tabular}{|c|c|c|c|}
\hline Соединение & $\rho, \Gamma / \mathrm{cm} 3$ & $\mathrm{~T}_{\text {пл, }}{ }^{\circ} \mathrm{C}$ & $-\Delta H_{\text {обр }}^{\circ}$ кДж/моль \\
\hline $\mathrm{MgAl}_{2} \mathrm{O}_{4}$ & 3,58 & 2135 & 2307,8 \\
\hline $\mathrm{TiB}_{2}$ & $4,45-4,50$ & 2850 & 293,3 \\
\hline $\mathrm{MgTiO}_{3}$ & 3,91 & $1630(1680)$ & 1569,6 \\
\hline$\alpha-\mathrm{Al}_{2} \mathrm{O}_{3}$ & 3,99 & 2045 & 1675,0 \\
\hline
\end{tabular}

На рис. 1 представлена термограмма процесса горения системы $\mathrm{TiB}_{2}$ (75 \% масс.) + $\mathrm{MgAl}_{2} \mathrm{O}_{4}$ (25\% масс.). Как видно из рисунка, максимальная температура синтеза составляет
$2300{ }^{\circ} \mathrm{C}$, что выше температуры плавления шпинели.

Синтез алюмомагнезиальной шпинели протекает при меньших температурах (рис. 2). 
CB-синтез TiB2-MgAl2O4 композитов для жаростойких покрытий

Воспламенение происходит при температуре $\sim 330{ }^{\circ} \mathrm{C}$ и достигает максимальной температуры процесса $\sim 1500{ }^{\circ} \mathrm{C}$, что ниже температуры плавления $\mathrm{TiB}_{2}$.

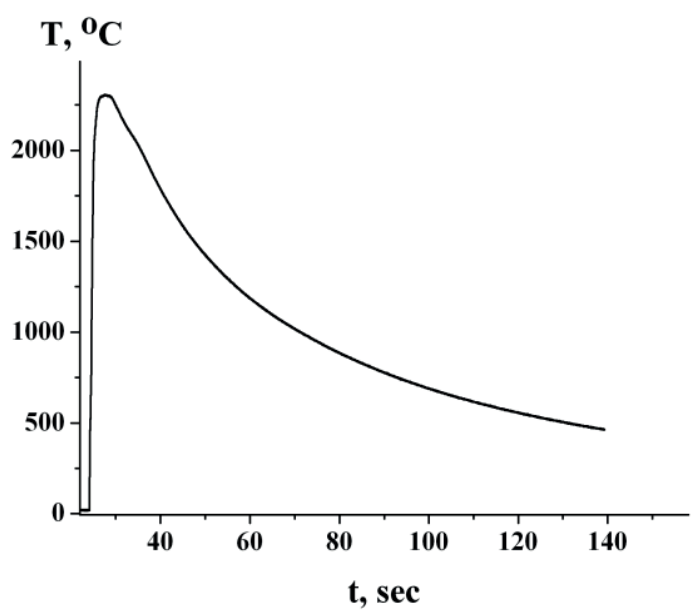

Рис. 1. Термограмма процесса горения системы $75 \%$ мacc. $\mathrm{TiB}_{2}+25 \%$ мacc. $\mathrm{MgAl}_{2} \mathrm{O}_{4}$

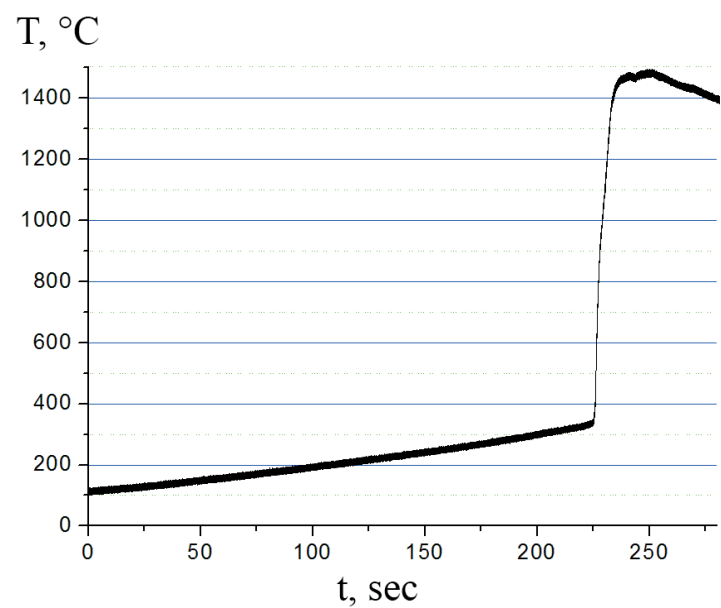

Рис. 2. Температурно-временной профиль CBсинтеза алюмомагнезиальной шпинели, шихта которой состоит из смеси $\mathrm{MgO}, \mathrm{Al}_{2} \mathrm{O}_{3}$, $\mathrm{Mg}\left(\mathrm{NO}_{3}\right)_{2} \cdot 6 \mathrm{H}_{2} \mathrm{O}, \mathrm{Al}$ и $\mathrm{B}(4 \%$ масс.)

В зависимости от содержания вводимой шпинели в состав композита на основе $\mathrm{TiB}_{2}$, полученного первым способом, наблюдается изменение микроструктуры образцов. При количестве $\mathrm{MgAl}_{2} \mathrm{O}_{4}<10 \%$ наблюдаются зерна диборида титана, не полностью окруженные затвердевшим расплавом $\mathrm{MgAl}_{2} \mathrm{O}_{4}$. Большое количество вводимой $\mathrm{MgAl}_{2} \mathrm{O}_{4}$ (40 \% масс.) формирует неоднородную структуру, включающую в себя отдельные области, состоящие из диборида титана и алюмомагнезиальной шпинели. Наилучшие результаты получаются при содержании шпинели в количестве $25 \%$ масс. (рис. 3). Микроструктура состоит из мелких зерен $\mathrm{TiB}_{2}$ (светлые кристаллы), полностью окруженных шпинелью (тёмные области).
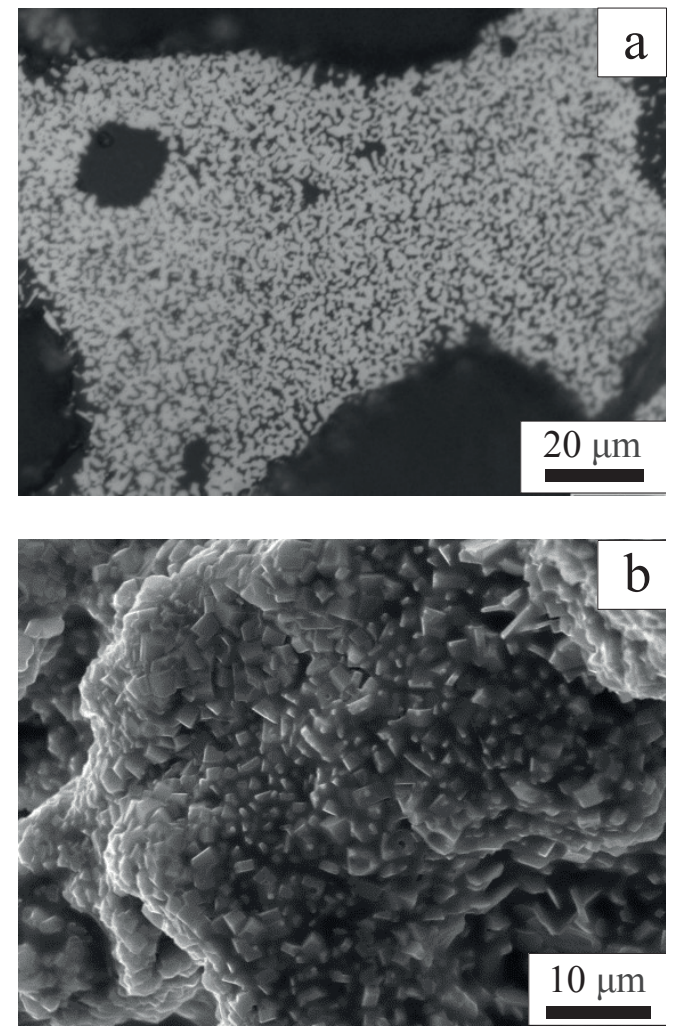

Рис. 3. Микроструктуры СВС-композитов на основе диборида титана с добавлением $25 \%$ $\mathrm{MgAl}_{2} \mathrm{O}_{4}$, где (a) - оптический микроскоп Axiovert $200 \mathrm{M}$ и (b) - растровый электронный микроскоп SEM-515 (Philips)

В результате исследования микроструктуры установлено, что добавка $25 \% \mathrm{MgAl}_{2} \mathrm{O}_{4}$ привела к существенному уменьшению кристаллов $\mathrm{TiB}_{2}$ ( 2 мкм), которые окружены застывшим расплавом алюмомагнезиальной шпинели.

Рентгенофазовый анализ исследуемых образцов, приведенный на рис. 4, показал, что в составе алюмомагнезиальной шпинели содержится $12 \%$ масс. $\mathrm{Al}_{2} \mathrm{O}_{3}$. Как видно из рисунка, шпинель определяется в композите, содержащем $25 \%$ масс. $\mathrm{MgAl}_{2} \mathrm{O}_{4}$, хотя металлографически шпинель идентифицируется уже при содержании $10 \%$ масс.

ИК-спектроскопические исследования композита, содержащего $25 \%$ масс. $\mathrm{MgAl}_{2} \mathrm{O}_{4}$, показали, что в его составе, наряду с $\mathrm{TiB}_{2}, \mathrm{MgAl}_{2} \mathrm{O}_{4}$ и $\alpha-\mathrm{Al}_{2} \mathrm{O}_{3}$, содержится незначительно $\mathrm{MgTiO}_{3}$ (рис. 5).

На рис. 5 (кривая 1) наблюдаются две основные полосы поглощения с максимумами при $692,0 \mathrm{~cm}^{-1}$ и 540,0 см-1, относящиеся к тетраэдрически координированному магнию $\mathrm{MgO}_{4}$ и октаэдрически координированному алюминию $\mathrm{AlO}_{6}$ алюмомагнезиальной шпинели. Неупорядоченность структуры шпинели, приводящая к изменению силы связи в катионной подрешетке шпинели, проявляется появлением по- 
лосы поглощения при 558,7 см-1 [8]. Небольшой пик в интервале частот 800-900 см с $^{-1}$ свидетельствует о присутствии $\mathrm{Al}_{2} \mathrm{O}_{3}$ в составе шпинели (кривая 3).

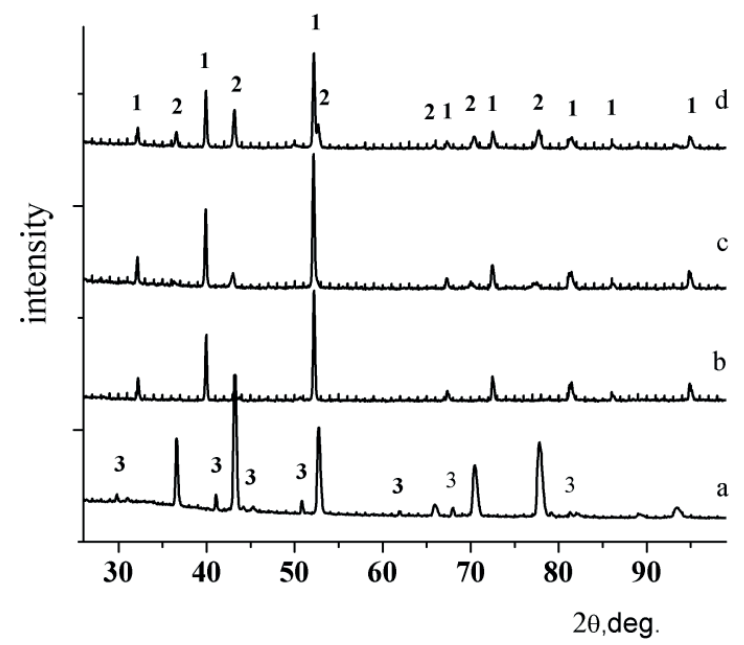

Рис. 4. Дифрактограммы композитов на основе $\mathrm{TiB}_{2}$ с различным содержанием алюмомагнезиальной шпинели: (a) $-\mathrm{MgAl}_{2} \mathrm{O}_{4}$, (b) $-\mathrm{TiB}_{2}+10 \% \mathrm{MgAl}_{2} \mathrm{O}_{4}$, (c) $-\mathrm{TiB}_{2}+25 \%$ $\mathrm{MgAl}_{2} \mathrm{O}_{4},(\mathrm{~d})-\mathrm{TiB}_{2}+40 \% \mathrm{MgAl}_{2} \mathrm{O}_{4} ; 1-\mathrm{TiB}_{2}, 2-$ $\mathrm{MgAl}_{2} \mathrm{O}_{4}, 3-\mathrm{Al}_{2} \mathrm{O}_{3}$

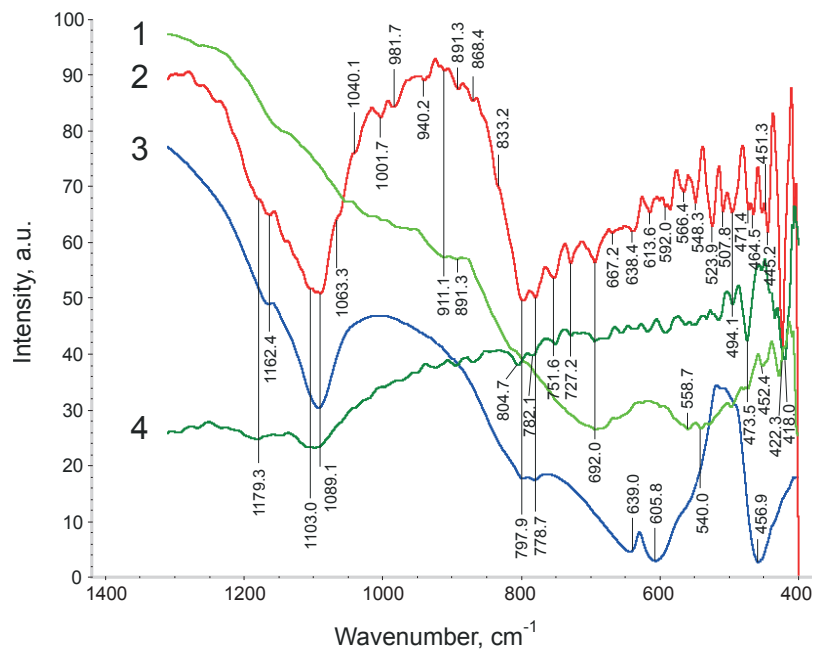

Рис. 5. ИК-спектры в интервале частот 400-1300 см-1: (1) - $\mathrm{MgAl}_{2} \mathrm{O}_{4},(2)$ - композит $\mathrm{TiB}_{2}-25 \%$ масс. $\mathrm{MgAl}_{2} \mathrm{O}_{4}$, (3) - серый корунд, (4) $-\mathrm{TiB}_{2}$

Диборид титана, содержащийся в композите, проявляется характерными полосами поглощения при 473, $5 \mathrm{~cm}^{-1}$ и $418 \mathrm{~cm}^{-1}$ (кривые 2 и 4).

В процессе горения системы $75 \%$ масс $\mathrm{TiB}_{2}+25 \%$ масс. $\mathrm{MgAl}_{2} \mathrm{O}_{4}$ максимальная температура достигает $2300^{\circ} \mathrm{C}$, что приводит к частичному разрушению $\mathrm{MgAl}_{2} \mathrm{O}_{4}$.

$$
\mathrm{MgAl}_{2} \mathrm{O}_{4} \stackrel{T}{\longrightarrow} \mathrm{Al}_{2} \mathrm{O}_{3}+\mathrm{MgO}
$$

Наличие полос поглощения в спектре композита при 638,$4 ; 592,0$ и 464, 5 см ${ }^{-1}$, характерных для октаэдрически координированного алюминия $\mathrm{AlO}_{6}$, и присутствие полос тетраэдрически координированного алюминия $\mathrm{AlO}_{4}$ при 1089,1; 797,9 и $778,7 \mathrm{~cm}^{-1}$ указывает на содержание в продукте глиноземистой шпинели $\mathrm{AlOAl}_{2} \mathrm{O}_{3}$. Эта шпинель, имеющая температуру плавления $1980{ }^{\circ} \mathrm{C}$, обнаружена при получении электрокорунда в восстановительной среде $[1 ; 9 ; 10]$. Для сравнения, ИК-спектр корунда приведен на рис. 5 (кривая 3). Кроме того, в спектре композита на уровне шумов проявляются полосы поглощения при 940,$2 ; 727,2 ; 507,8$ и $451,3 \mathrm{~cm}^{-1}$, которые можно отнести к $\mathrm{MgTiO}_{3}$ [11]. Образование данного соединения возможно во время синтеза на границе фаз между $\mathrm{TiB}_{2}$ и $\mathrm{MgAl}_{2} \mathrm{O}_{4}$. Кислород и $\mathrm{MgO}$ могут заимствоваться при термическом распаде шпинели.

$$
\mathrm{MgO}+\mathrm{Ti}+\mathrm{O}_{2}=\mathrm{MgTiO}_{3}
$$

В результате мелкозернистой структуры данного композита его ИК-спектр (кривая 2) представляет собой огибающую линию по спектру алюмомагнезиальной шпинели с наложением многочисленных частот колебаний связей, относящихся к $\mathrm{TiB}_{2}$, корунду, глиноземистой шпинели и $\mathrm{MgTiO}_{3}$.

Как видно из табл. 1, все присутствующие в композите компоненты имеют высокие значения температур плавления, что делает данный керамический материал огнеупорным.

В процессе СВ-синтеза композитного материала из смеси оксидов $\mathrm{MgO}$ и $\mathrm{Al}_{2} \mathrm{O}_{3}$, нитрата магния $\mathrm{Mg}\left(\mathrm{NO}_{3}\right)_{2} \cdot 6 \mathrm{H}_{2} \mathrm{O}$ и порошков алюминия АСД- 4 , бора, с добавками $\mathrm{TiB}_{2}(10 \%$ масс. и $20 \%$ масс.) получен керамический материал, состоящий, согласно рентгенофазовому анализу, в основном, из смеси $\mathrm{MgAl}_{2} \mathrm{O}_{4}, \mathrm{TiB}_{2}$ и $\alpha-\mathrm{Al}_{2} \mathrm{O}_{3}$. $\mathrm{B}$ составе композита незначительно определяются оксид $\mathrm{Al}_{2} \mathrm{O}_{4}$, остаточный $\mathrm{MgO}$ и возможно $\mathrm{BN}$ (рис. 6). Наличие $\mathrm{BN}$ подтверждается ИКспектроскопическим анализом (рис. 7).

На ИК-спектрах композита с различным содержанием $\mathrm{TiB}_{2}$ в составе исходных реагентов наблюдаются как полосы поглощения тетраэдрически координированного магния $\left[\mathrm{MgO}_{4}\right]$ при $696,7 \mathrm{~cm}^{-1}$ и октаэдрически координированного алюминия $\left[\mathrm{AlO}_{6}\right]$ при $543,2 \mathrm{~cm}^{-1}$, относящиеся к алюмомагнезиальной шпинели, так и $\mathrm{TiB}_{2}$ при 1098,$2 ; 474,4$ и 418 cм$^{-1}$. Причем с увеличением содержания диборида титана в шихте наблюдается увеличение полосы поглощения при $418 \mathrm{~cm}^{-1}$ со сдвигом в низкочастотную область до $412 \mathrm{~cm}^{-1}$, что связано с незначительным окислением $\mathrm{TiB}_{2}$ и частичным замещением колебаний связи $\delta(\mathrm{Ti}-\mathrm{B})$ на $\delta(\mathrm{Ti}-\mathrm{O})$ с образованием оксида титана ТiO [8]. При $1651,7 \mathrm{~cm}^{-1}$ фиксируется незначитель- 
ное деформационное колебание $\delta(\mathrm{OH})$-группы воды, адсорбированной на дибориде титана. Присутствует полоса поглощения тетраэдрически координированного алюминия $\mathrm{AlO}_{4}$ при $\sim 780 \mathrm{~cm}^{-1}$, относящаяся к оксиду $\mathrm{Al}_{2} \mathrm{O}_{4}$, определяемому также рентгенофазовым анализом.

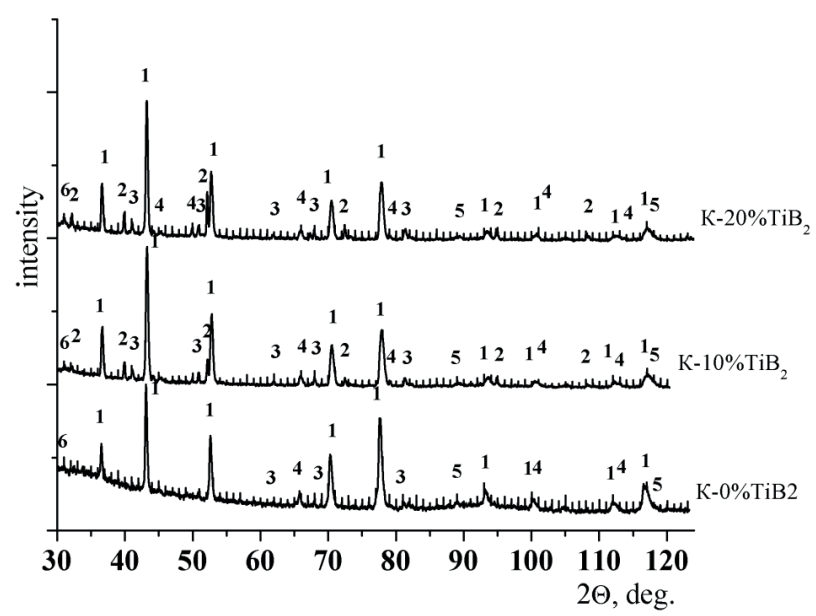

Рис. 6. Дифрактограммы композитов на основе $\mathrm{MgAl}_{2} \mathrm{O}_{4}$ с добавками $\mathrm{TiB}_{2}$ :

K-0 \% $\mathrm{TiB}_{2}$ - алюмомагнезиальная шпинель, полученная СВС методом; К-10 \% $\mathrm{TiB}_{2}$ - композит на основе алюмомагнезиальной шпинели, содержащий 10 \% $\mathrm{TiB}_{2}$; К-20\% $\mathrm{TiB}_{2}$ - композит на основе алюмомагнезиальной шпинели, содержащий $20 \% \mathrm{TiB}_{2}$

$1-\mathrm{MgAl}_{2} \mathrm{O}_{4}, 2-\mathrm{TiB}_{2}, 3-\alpha-\mathrm{Al}_{2} \mathrm{O}_{3}, 4-\mathrm{Al}_{2} \mathrm{O}_{4}, 5-$ $\mathrm{MgO}, 6-\mathrm{BN}$

Нитрид бора проявляется широкой полосой поглощения в интервале 1200-1600 см-1 (характерное плечо при 1272,6 cм-1) и колебаниями связей при 925,5 (плечо), 816,7 см-1, что указывает на гексагональную модификацию [12]. Он относится к тугоплавким $\left(\mathrm{T}_{\text {пл }}=2973{ }^{\circ} \mathrm{C}\right)$, термически устойчивым, мало реакционноспособным соединениям и используется для изготовления высокоогнеупорных материалов. Образование BN происходит из смеси оксидов азота, выделившихся при разложении шестиводного нитрата магния.

$$
\begin{aligned}
& 2 \mathrm{Mg}\left(\mathrm{NO}_{3}\right)_{2} \cdot 6 \mathrm{H}_{2} \mathrm{O}= \\
& =2 \mathrm{MgO}+12 \mathrm{H}_{2} \mathrm{O} \uparrow+\mathrm{O}_{2} \uparrow+4 \mathrm{NO}_{2} \uparrow
\end{aligned}
$$

Известно также, что при повышенных температурах (135-620 $\left.{ }^{\circ} \mathrm{C}\right)$ двуокись азота разлагается на монооксид азота и кислород, а монооксид азота $\mathrm{NO}$ при $800{ }^{\circ} \mathrm{C}$ окисляет бор с образованием оксида и нитрида бора одновременно [13].

$$
\begin{gathered}
2 \mathrm{NO}_{2}=2 \mathrm{NO}+\mathrm{O}_{2} \\
5 \mathrm{~B}+3 \mathrm{NO}=\mathrm{B}_{2} \mathrm{O}_{3}+3 \mathrm{BN}
\end{gathered}
$$

Действительно, наряду с нитридом бора определяется широкая полоса поглощения $\mathrm{B}_{2} \mathrm{O}_{3}$ с максимумами при 1477,3 и $1450 \mathrm{~cm}^{-1}$, соответствующими ассиметричным валентным колебаниям связи В-О в плоском треугольнике $\left[\mathrm{BO}_{3}\right]$ и колебаниям самих треугольных группировок $\left[\mathrm{BO}_{3}\right]$ при 880,7 cм-1, что указывает на частичное окисление бора $[14 ; 15]$.

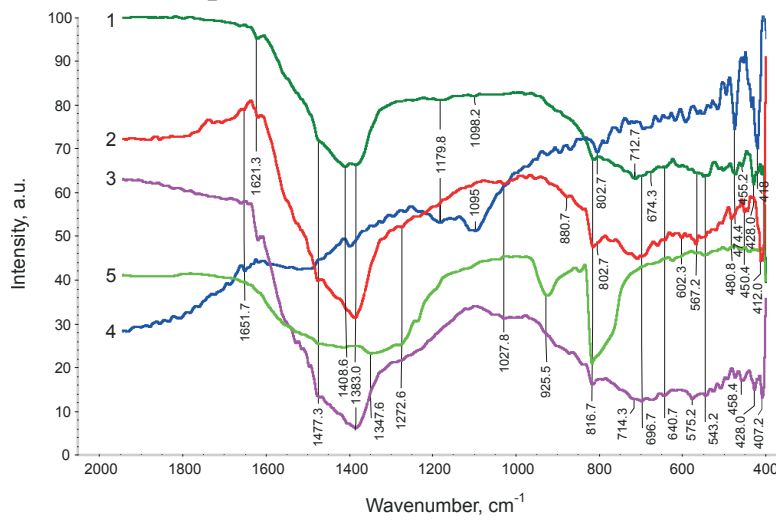

Рис. 7. ИК-спектры в интервале частот 400-2000 см-1: (1) - композит ( $\mathrm{TiB}_{2}-10 \%$ масс.), (2) - композит ( $\mathrm{TiB}_{2}$ $20 \%$ масс.), (3) - $\mathrm{MgAl}_{2} \mathrm{O}_{4}$ (СВC-метод), (4) - $\mathrm{TiB}_{2},(5)$ - нитрид бора (гексагональный)

В инфракрасном диапазоне при 720; 567,2 и 450,4 см-1 проявляется соединение, имеющее структуру аналогичную структуре перовскита [16]. К такому соединению может относиться и титанат магния $\mathrm{MgTiO}_{3}$.

Оптические исследования подтверждают частичное разрушение диборида титана. На микрофотографии композита (20\% масс. $\left.\mathrm{TiB}_{2}\right)$ видно, что частицы $\mathrm{TiB}_{2}$, находящиеся в матрице из алюмомагнезиальной шпинели, окружены ореолом из частиц желтого цвета (рис. 8). Вследствие того, что синтез полученного материала проводился на воздухе в агрессивной окислительной среде, наблюдается частичное окисление кристаллов $\mathrm{TiB}_{2}$ по поверхности и по границам раздела зерен с образованием оксида ТiO.

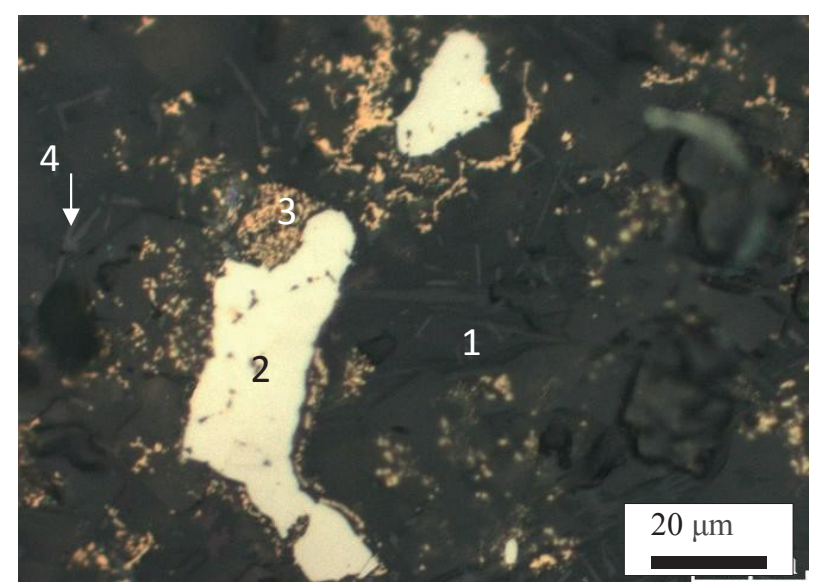

Рис. 8. Микроструктура СВС-композита, полученного вторым способом, где $1-\mathrm{MgAl}_{2} \mathrm{O}_{4}$, $2-\mathrm{TiB}_{2}, 3-\mathrm{TiO}, 4-\mathrm{Al}_{2} \mathrm{O}_{3}$ 
Как показали исследования, лучшие результаты получены первым способом. Материал $\left(\mathrm{TiB}_{2}+25 \% \mathrm{MgAl}_{2} \mathrm{O}_{4}\right)$ имеет мелкозернистую структуру, состоящую из зерен $\mathrm{TiB}_{2}$, окруженных алюмомагнезиальной шпинелью. Образующаяся поверхностная прослойка из $\mathrm{MgAl}_{2} \mathrm{O}_{4}$ на границе зерен $\mathrm{TiB}_{2}$ выступает в роли блокирующей защиты от окисления диборида титана и препятствует росту кристаллов $\mathrm{TiB}_{2}$. В процессе синтеза композита происходит частичное разрушение шпинели, о чём свидетельствуют незначительные примеси корунда и $\mathrm{MgTiO}_{3}$.

Во втором случае наблюдаются крупные частицы диборида титана, хаотично разбросанные в алюмомагнезиальной матрице. Частичное окисление кристаллов $\mathrm{TiB}_{2}$ по поверхности и границам зерен приводит к образованию оксида $\mathrm{TiO}$, кроме того на уровне микропримесей обнаруживается $\mathrm{MgTiO}_{3}$.

Измерения микротвердости, проведенные на микротвердомере ПМТ-3, показали, что для композита $75 \%(\mathrm{Ti}+2 \mathrm{~B})+25 \% \mathrm{MgAl}_{2} \mathrm{O}_{4}$ она несколько выше и составляет 24,02 ГПа в отличие от композита $90 \%(\mathrm{Ti}+2 \mathrm{~B})+10 \% \mathrm{MgAl}_{2} \mathrm{O}_{4}$ co значением микротвердости 22,56 ГПа. По форме отпечатка, оставленного пирамидкой, можно сделать вывод, что композит $75 \%(\mathrm{Ti}+2 \mathrm{~B})+25 \%$
$\mathrm{MgAl}_{2} \mathrm{O}_{4}$ является менее хрупким (отсутствуют трещины по углам отпечатка). Введение добавок $\mathrm{MgAl}_{2} \mathrm{O}_{4}$ способствует формированию более плотных структур композитов на основе $\mathrm{TiB}_{2}$.

\section{Закмючение}

В процессе синтеза композита первым способом происходит частичное разрушение шпинели, о чём свидетельствуют незначительные примеси корунда, глиноземистой шпинели и $\mathrm{MgTiO}_{3}$, что доказывается ИК-спектроскопией.

Во втором случае, согласно рентгенофазовому анализу и ИК-спектроскопии, происходит частичное окисление диборида титана и, наряду с образованием основных фаз $\left(\mathrm{MgAl}_{2} \mathrm{O}_{4}, \mathrm{TiB}_{2}\right)$, наблюдается образование корунда, оксида $\mathrm{Al}_{2} \mathrm{O}_{4}$, $\mathrm{BN}, \mathrm{B}_{2} \mathrm{O}_{3}, \mathrm{TiO}$ и $\mathrm{MgTiO}_{3}$.

Показано, что структура с равномерным распределением зерен $\mathrm{TiB}_{2}$ в алюмомагнезиальной матрице получена первым способом с применением $25 \%$ масс. $\mathrm{MgAl}_{2} \mathrm{O}_{4}$.

Образующаяся прослойка из $\mathrm{MgAl}_{2} \mathrm{O}_{4}$ на границах зерен $\mathrm{TiB}_{2}$ выступает в роли блокирующей защиты от окисления диборида титана и препятствует росту кристаллов $\mathrm{TiB}_{2}$.

\section{Список литературы}

1. Хорошавин Л. Б. Шпинелидные наноогнеупоры. Екатеринбург : УрО РАН, 2009. 600 с.

2. Omid E. K., Naghizadeh R., Rezaie H. R. Synthesis and comparison of $\mathrm{MgAl}_{2} \mathrm{O}_{4}-\mathrm{Ti}(\mathrm{C}, \mathrm{N})$ composites using aluminothermic-carbothermal reduction and molten salts routes // Journal of Ceramic Processing Research, 2013, vol. 14 , no. 4 , pp. $445-447$.

3. Zaki Z .I, Ahmed Y. M. Z., Abdel-Gawad S. R. In-situ synthesis of porous magnesia spinel/ $/ \mathrm{TiB}_{2}$ composite by combustion technique // Journal of the Ceramic Society Japan, 2009, vol. 117 (1366), pp. 719-723.

4. Horvitz D., Gotman I. Pressure-assisted SHS synthesis of $\mathrm{MgAl}_{2} \mathrm{O}_{4}-\mathrm{TiAl}$ in Situ composites with interpenetrating networks // Acta Materialia, 2002, vol. 50, no. 8, pp.1961-1971.

5. Мержанов А. Г. Процессы горения и синтеза материалов. Черноголовка : Издательство ИСМАН, 1998. 511 с.

6. Самсонов Г. В., Буланкова Т. Г., Бурыкина Ф. Л., Знатокова Т. Н. Физико-химические свойства окислов: справочник. М. : Металлургия, 1969. 456 с.

7. Рузинов Л. П., Гуляницкий Б. С. Равновесные превращения металлургических реакций. М. : Металлургия, $1975.416 \mathrm{c}$.

8. Барабанов В. Ф., Гончаров Г. Н., Зорина М. Л. Современные физические методы в геохимии. Л. : Изд-во Ленинградского ун-та, 1990. $391 \mathrm{c.}$

9. Чернякова К. В., Врублевский И. А., Ивановская М. И., Котиков Д. А. Примесно-дефектная структура анодного оксида алюминия, сформированного методом двустороннего анодирования в растворе винной кислоты // Журнал прикладной спектроскопии. 2012. Т. 79, № 1. С. 83-89.

10. Солодкий Е. Н., Солодкий Н. Ф. Причины окрашивания корундовой керамики // Стекло и керамика. 2000. № 11. С. 24-26.

11. Накамото К. ИК спектры и спектры КР неорганических и координационных соединений / пер. с англ. под редакцией Ю. А. Пентина. М. : Мир, 1991. 536 с.

12. Бланк В. Д., Эстрин Э. И. Фазовые превращения в твердых телах при высоком давлении. М. : Физматлит, 2011. $412 \mathrm{c}$.

13. Лидин Р. А., Молочко В. А., Андреева Л. Л. Неорганическая химия в реакциях: справочник. М. : Дрофа, 2007. $637 \mathrm{c}$. 
14. Баличева Т. Г., Лобанева О. А. Электронные и колебательные спектры неорганических и координационных соединений. Л. : Изд-во ЛГУ, 1983. 117 с.

15. Лавренов А. В., Булучевский Е. А., Карпова Т. Р., Моисеенко М. А. и др. Синтез, строение и свойства компонентов моторных топлив // Химия в интересах устойчивого развития. 2011. Т. 19. № 1. С. 87-95.

16. Перовскит [Электронный ресурс]. URL: http://natural-museum.ru/mineral/перовскит (дата обращения: 13.09.2018).

\title{
SH-SYNTHESIS OF $\mathrm{TiB}_{2}-\mathrm{MgAl}_{2} \mathrm{O}_{4}$ COMPOSITES FOR HEAT- RESISTANT COATINGS
}

\author{
N. I. Afanasyev, N. I. Radishevskaya, O. K. Lepakova, \\ A. Yu. Nazarova, W. D. Kitler \\ Tomsk Scientific Centre SB RAS, Tomsk, Russian Federation
}

\begin{abstract}
Metal borides are known to be widely used as heat-insulating materials, but their efficiency significantly reduces under high-temperature oxidizing conditions. To increase the heat resistance of structural materials based on titanium diboride and prevent the growth of $\mathrm{TiB}_{2}$ crystals, chemically-resistant refractory magnesium-aluminate spinel was used. The purpose of this work was to study the structure of the TiB $B_{2}-$ $\mathrm{MgAl}_{2} \mathrm{O}_{4}$ composite obtained by the method of self-propagating high-temperature synthesis using two approaches. The first approach is the self-propagating high-temperature synthesis of titanium diboride from its elements with the addition of magnesium-aluminate spinel. Another approach to the obtaining of a heatresistant composite material is the self-propagating high-temperature synthesis of magnesium-aluminate spinel with the addition of titanium diboride. The best results were obtained using the first approach. $A$ structure with a uniform distribution of fine TiB $B_{2}$ grains was synthesized by adding $25 \% \mathrm{wt}$. $\mathrm{MgAl}_{2} \mathrm{O}_{4}$. The compositions were investigated using X-ray diffraction (DRON-3M, filtered $\mathrm{Cu}-\mathrm{k}_{\alpha}$-radiation), IR spectroscopy (Nicolet 5700) and scanning electron microscopy (Philips SEM 515). The obtained material was a composite in which $\mathrm{TiB}_{2}$ particles with a size not exceeding 5 microns were uniformly distributed in the matrix of magnesium-aluminate spinel.
\end{abstract}

Keywords: titanium diboride, magnesium-aluminate spinel, self-propagating high-temperature synthesis, composites.

\section{References}

1. Horoshavin L.B. Shpinelidnye nanoogneupory [Spinel Nanorefractory Materials]. Ekaterinburg, UB RAS, 2009, 600 p. (In Russian)

2. Omid E. K., Naghizadeh R., Rezaie H. R. Synthesis and comparison of $\mathrm{MgAl}_{2} \mathrm{O}_{4}-\mathrm{Ti}(\mathrm{C}, \mathrm{N})$ composites using aluminothermic-carbothermal reduction and molten salts routes // Journal of Ceramic Processing Research, 2013, vol. 14 , no. 4, pp. 445-447.

3. Zaki Z. I, Ahmed Y. M. Z., Abdel-Gawad S. R. In-situ synthesis of porous magnesia spinel/TiB ${ }_{2}$ composite by combustion technique // Journal of the Ceramic Society Japan, 2009, vol. 117 (1366), pp. 719-723.

4. Horvitz D., Gotman I. Pressure-assisted SHS synthesis of $\mathrm{MgAl}_{2} \mathrm{O}_{4}$-TiAl in Situ composites with interpenetrating networks // Acta Materialia, 2002, vol. 50, no. 8, pp.1961-1971.

5. Merzhanov A. G. Processy goreniya i sinteza materialov [Processes of Burning and Materials Synthesis]. Chernogolovka, ISMAN, 1998, 511 p. (In Russian)

6. Samsonov G. V., Bulankova T. G., Burykina F. L., Znatokova T. N. Fiziko-himicheskie svojstva okislov [Physicalchemical properties of oxides]. Metallurgy, 1969, 456 p. (In Russian)

7. Ruzinov L.P., Gulyanitzkii B. S. Ravnovesnye prevrashcheniya metallurgicheskih reakcij [Equilibrium transformation of metallurgical reactions]. Metallurgy, 1975, 416 p. (In Russian)

8. Barabanov V. F., Goncharov G. N., Zorina M. L. Sovremennye fizicheskie metody v geohimii [Modern Physical Methods on Geochemistry]. Leningrad University, 1990, 390 p. (In Russian)

9. Chernyakova K. V., Vrubelevskii I. A., Ivanovskaya M. I., Kotikov D. A. Primesno-defektnaya struktura anodnogo oksida alyuminiya, sformirovannogo metodom dvustoronnego anodirovaniya v rastvore vinnoj kisloty [Defective structure of anode alumina oxide, formed by method of bilateral anodic oxidation] // J. Appl. Spectrosc, 2012, vol. 79, no. 1, pp. 83-89. (In Russian) 
10. Solodkii E. N., Solodkii N. F. Prichiny okrashivaniya korundovoj keramiki [Reasons for coloring corundum ceramics] // Glass Ceram, 2000, no. 11, pp. 24-26. (In Russian)

11. Nakamoto K. IK-Spektry $i$ Spektry KR Neorganicheskikh i Koordinatsionnykh Soedinenii [Infrared and Raman Spectra of Inorganic and Coordination Compounds]. Mir, 1991, 536 p. (In Russian)

12. Blank V. D., Estrin E. I. Fazovye prevrashcheniya v tverdyh telah pri vysokom davlenii [Phase transformations in solids at high pressure]. Moscow, Fizmatlit, 2011, 412 p. (In Russian)

13. Lidin R. A., Molochko V. A., Andreeva L. L. Neorganicheskaya himiya v reakciyah [Inorganic chemistry in reactions]. Moscow, Drofa, 2007, 637 p. (In Russian)

14. Balicheva T. G., Lobaneva O. A. Elektronnye i kolebatel'nye spektry neorganicheskih i koordinacionnyh soedinenij [Electronic and vibrational spectra of inorganic and coordination compounds]. Leningrad, Leningrad State University, 1983, 117 p. (In Russian)

15. Lavrenov A. V., Bulychevsky E. A., Karpova T. R., Moiseenko M. A. Sintez, stroenie i svojstva komponentov motornyh topliv [Synthesis, structure and properties of components of motor fuels] // Chemistry in the interests of sustainable development, 2011, vol. 19, no. 1, pp. 87-95. (In Russian)

16. Perovskit. Available at: http://natural-museum.ru/mineral/perovskite (accessed 13.09.2018). 